\title{
Effect of Instructional Guidelines on Mothers' Anxiety Regarding Behavioral Changes Among Children with Autism during Corona Virus Disease
}

\author{
Manal Mohamed Ahmed Ayed ${ }^{1}$, Safaa Mustafa Mohamed ${ }^{2}$, Sanaa Mostafa khalifa Ali $^{3} \&$ Eman Abd-Elaziz \\ Mohamed ${ }^{4}$. \\ 1. Assistant Professor of Pediatric Nursing, Faculty of Nursing, Sohag University, Egypt \\ ${ }^{2 .}$ Lecture of Psychiatric Nursing, Faculty of Nursing, Sohag University, Egypt, \\ ${ }^{3 .}$ Lecture of Psychiatric Nursing, Faculty of Nursing, Sohag University, Egypt, \\ ${ }^{4 .}$ Lecture of Pediatric Nursing, Faculty of Nursing, South Valley University, Egypt.
}

\begin{abstract}
Corona virus pandemic 2019 (COVID-19) lockdown has a negative psychological impact on Egyptian mothers of children with autism. As a result of social distancing, both mothers and Autism Spectrum Disorder (ASD) were not supported by face to face by care and not able to participate in external care and staying at home. Aim: The study was aimed to evaluate the effect of instructional guidelines on mothers' anxiety regarding behavioral changes among children with autism during corona virus disease. Subjects and method: in this study quasi-experimental research design was used on a convenient sample composed of 130 mothers having children with autism residing at Sohag Governorate, Egypt. Five tools were used in this study: A self-administered questionnaire, the Adaptive Behaviour Assessment System, The ASD Behaviour Inventory, The Short Sensor and Beck Anxiety Inventory (BAI). The link of the survey using the questionnaire, the scale, and the instructional guidelines were sent to the participants' mothers through Facebook and Whats App groups. Results: The study showed an increase in repetitive and restricted behaviors among more than one-third of the participants. Mothers' anxiety level was severe before the implementation of the guideline and became low after guidelines implementation. Conclusion: The instructional guidelines were effective in reducing mothers' anxiety regarding behavioral changes among children with autism during coronavirus pandemic outbreaks. Recommendations: Educational programs about the meanings of behavioral changes of their children, COVID -19 and its preventive measures should be taught to all mothers and psychological support is essential for them.
\end{abstract}

\section{Keywords: Anxiety, Autism, Corona Virus, Instructional Guidelines \& Mothers.}

\section{Introduction}

Corona virus pandemic disease (COVID-19) is a highly infectious respiratory disease that spread around the world, causing public health crisis disease, this rapid rise in confirmed cases and deaths has caused anxiety among mothers and autistic children (Bai et al., 2020). Many risk factors related to physical distancing and lead to increasing in occurring mental health issues such as routine changes, social isolation, and deficiency of communication may affect children with ASD (Cassidy et al., 2020). Incidence of children comprised $22 \%$ population, the most recent data, available through the CDC (CDC, 2020), Hospitalization rates among children are significantly lower than hospitalization rates in adults with COVID-19, as children may have less severe illness from COVID-19 compared to adults (Bixler et al., $2020, \&$ Leeb et al., 2020)

Seif Eldin, et al., (2008) reported that the prevalence rate of $33.6 \%$ among children with developmental disabilities in Egypt. While the Social Solidarity Ministry has reported that there are 800,000 people with ASD in Egypt (Al-Masry Al-Youm, 2017).
Children with ASD with severe symptoms not know what occur around them and why school is lockdown and routines changed. Hence, autistic children may find difficulty adapting for new environmental changes (Christensen et al., 2018), and making autistic children more adaptive population needs concentration regarding the topic of the preventive measures during COVID-19 (Istituto Superiore di Sanità, 2020).

Unexpected changes form children as communication impairments may be associated with problems of receptive and expressive communication, limited verbal or nonverbal skills, and social communication deficits (Logan et al., 2017). Since the corona virus pandemic hit the world, people try to cope with the virus and the changes that have brought in their lives. This new analysis finds a gap in mothers' worries and their views on the reported effects of corona virusrelated stress on their children's mental health and wellbeing. These causes have physical and psychological effects on mothers. In this context, most mothers experience reactions to stress, anxiety, and depression (Campbell, 2020). 
Fear and anxiety can be expressed through behavioral changes as eating patterns, sleep/wake rhythms, increase in the repetitive behaviors, increase in irritability and agitation and decrease in care (Hume et al., 2020).

Stress and anxiety regarding behavioral changes reflect a higher level of worry for mothers. Mothers are more likely to be anxious about the health and safety of their children, family members, or other people. Mothers are likely to worry about their children regarding behavioral changes among children with autism during corona virus disease because have a major negative impact on their mental health and have experienced specific adverse effects due to anxiety related to this infection and behavioral changes during corona virus pandemic (Lunna et al., 2020).

Nursing management regarding COVID-19 should focus on preventing the spread of infection. Pediatric nurses have an important role as teachers and advisors in educating service users and caregivers, in providing health education in society, and in facilitating the development of other multidisciplinary team members. They should teach the mothers to apply the ideal hand washing technique, follow the social distance, use the disinfectant materials such as alcohol, avoid shaking hands, put a tissue when coughing or sneezing on the mouth and nose, and wearing a mask to prevent the infection transmission. Also, educating the mothers to encourage the child not to touch the eyes, nose, and mouth, about appropriate hand washing after contact with others, sneezing, or coughing and they should be discouraged from sharing towels, washcloth, and get a separate bottle for each family member (WHO, 2020). Programs for rehabilitation for autistic children are important for mothers' support in order to provide them good management of problems of autism and increase the children's communication and social relations. Staying at houses and the closure of facilities of daycare has a bad effect on outcomes, increasing the risk of problems (Chaturvedi, 2020).

\section{Significance of the study}

There is an increased flow rate of children with COVID-19 in Egyptian 2020. Mothers face a unique set of challenges as they attempt to balance the needs of their children with autism, and they are worried from corona virus-related stress on their wellbeing and their behavioral change during COVID-19 (Ministry of Health \& Population in Egypt “MOHP", 2020).

\section{Aim of the study}

The study was aimed to evaluate the effect of instructional guidelines on mothers' anxiety regarding behavioral changes among children with autism during COVID-19.

\section{Research hypothesis}

Mothers of autistic children will have a low level of anxiety regarding behavioral changes among autistic children during COVID-19 after implementation of the instructional guidelines.

\section{Subjects \& Methods \\ Research design}

A quasi-experimental research design (pre and posttest) was used in this study.

Setting:

The study conducted at Sohag Governorate, Egypt. Subjects

A convenient sample of a total of 130 mothers and their autistic children were included in the study to achieve the aim of this study. It included 130 mothers having children with autism in the previous setting through a Google form spreadsheet which presented in Facebook and Whats App groups. All of the studied mothers meet the following inclusion criteria as educated mothers, free from physical, mental, chronic disease, free from cognitive disease, no history of mental illness, over the age of 18 years old, who are living in the same house with their children, and willingness to participate in the study. The children had the following criteria: Age ranged from 5 -12 years, both sexes and free from other chronic physical illnesses.

\section{Tools of data collection}

Five tools were used in the current study as the following:

Tool I: A self-administered questionnaire (pre and post-test format) was developed by the researchers after reviewing the related literature and research studies (Ministry of Health and Population Egypt (2020). It included the following two parts:

Part (1): Socio-demographic characteristics of the studied subjects which divided into:

a- Characteristics of the studied mothers: This included age, educational level, residence, working status, family history of autism, and consanguinity.

b- Characteristics of the studied children: This involved age, gender, and educational level, child's medical history which includes: the age when autism was discovered duration and degree of disability.

Part (2)

a- Mothers' knowledge about COVID -19: Which included: definition, mode of transmission, clinical pictures, complications/ risks, high-risk persons, treatment, personal protective measures as hand washing, wearing a mask, use disinfectant materials like alcohol, avoid shaking hands, put a 
tissue when coughing or sneezing on the mouth and nose and social distance.

b- Mothers' information about Autism: The meaning of autism and its causes, the common age of autism occurrence, the manifestations of autism and effect of autism on the child, diagnosis, duration of treatment, needs of the child, treatment approaches, side effects of drugs, rehabilitation and how to deal with their children, that was introduced to mothers through the instructional guidelines by the Whats App and Face book groups.

Scoring system for mothers' knowledge about COVID - 19 and rehabilitation

The total mothers' knowledge percentages were calculated for known and unknown answers. Complete correct answer was given two marks, incomplete correct answer given one mark and zero mark given for wrong or unknown answers. For each area of knowledge, the scores of the items were summed up and the total answers were divided by the number of the items, giving a mean score for the knowledge. Then, these scores were converted to a percentage score. Mothers' knowledge was considered satisfactory if the percentage score was $60 \%$ or more and unsatisfactory if was less than $60 \%$.

B-Mothers reported practice about the ideal hand washing technique which was demonstrated and measured through a video by the Whats App and Face book group.

Scoring system for mothers' reported practice The steps of the procedure of hand washing that was done correctly were scored (1), and the items not done or incorrectly done were scored zero. For each area, the scores of the items were summed up, and the total was divided by the number of the items, giving the mean score for the part. These scores were converted to a percentage score. Mother's performance was considered satisfactory if the percentage score was $60 \%$ or more and unsatisfactory if was less than $60 \%$.

Tool II: The Adaptive Behavior Assessment System (ABAS)

The researchers was used this scale which provided the individualized measure of adaptive assessment (Harrison and Oakland 2003). It is a comprehensive measure of adaptive functioning in the home and community. It consists of 232 items, each rated on a scale from $0=$ Is Not Able to 30 Always /Almost Always. It includes 10 skill areas (Communication, Community Use, Functional Academics, Home Living, Health and Safety, Leisure, Self-Care, Self-Direction, Social, and Work [Work is only for individuals $\geq 17]$ ) which are combined to form three composites including Conceptual (CON; as well as an overall General
Adaptive Composite (GAC). Composite scores have a norm-referenced Mean \pm SD $(100 \pm 15)$ and skill area scores have a norm-referenced Mean \pm SD $10 \pm$ (03). Reported average internal consistency reliability estimates range from .95-.98 for composites and .86.93 for skill area scales. For the 5-12 children age range, corrected test-retest reliabilities were $\geq .87$ for all skill area scores and composites. Validity is supported in age-difference sensitivities (i.e., increased scores for each skill area as age increases). Concurrent validity is supported in moderate-tostrong correlations with other measures of adaptive functioning.

Tool III: The ASD Behavior Inventory (ASDBI):

It is considered a good rating scale for parents; it was included subscales that measured maladaptive behaviors. The maladaptive subscales were administered as following: (a) Arousal Problems used to assess hyperactivity, fears induced by new situations and problems with sleeping; and (b) Aggressiveness to assess both self and other-directed aggression, along with general moodiness and irritability (Cohen \& Sudhalter, 2005).

Tool IV: The Short Sensory Profile

This scale conducted by (McIntosh et al., 1999) to assess sensory symptoms through seven topics which containing 38 items to identify how the child sensory inputs through the sensory systems. The Taste/Smell Sensitivity subscale was also tested and parents were asked to indicate how often their children expressed their sensory behaviors. Scores are assigned on a five-point Likert scale ranging from "always" $=0$ to "never" $=4$. Low scores are indicative of frequent dysfunctional behaviors.

Tool (V): Beck Anxiety Inventory (BAI)

It was used as a data collection device in this study. The (BAI) adopted by (Beck et al., 1988), which was developed to measure the severity and symptoms of the anxiety, it consists of 21 questions and total scores ranged from 0 to 63 . It measures the physical, emotional, and cognitive aspects of anxiety and fear of losing control. The score for each item ranges from 0 to 3.The maximum score on the scale. Beck's original version had internal consistency with a Cronbach's Alpha of 0.92, and a retest reliability coefficiency of $\mathrm{r}=0.75$.

Validity

The BAI items were moderately correlated with the revised Hamilton Anxiety Rating Scale (.51) and mildly correlated with the Hamilton Depression Rating Scale (.25).

Scoring

The total score is calculated by finding the sum of the 21 items.

The score of $0-21=$ mild anxiety

The score of 22-35 = moderate anxiety 
A score of 36 and above = sever levels of anxiety.

The instructional guidelines

The researchers designed and implemented the guidelines about COVID- 19 in the Arabic language after reviewing the related literature (Ministry of Health and Population Egypt (2020) based on the assessment of the actual needs of the studied mothers. It covered the theoretical knowledge and the reported practical procedure. The theoretical part included knowledge about the definition, and clinical picture, mode of transmission, diagnostic tests, treatment, and preventive measures regarding COVID-19 and mothers' knowledge about autism; the meaning of autism and its causes, common age of autism occurrence, the manifestation of autism and effect of autism on the child, diagnosis, duration of treatment, needs of the child, treatment approaches, side effects of drugs, rehabilitation and how to deal with their children. The reported practical part included the ideal technique of hand washing to prevent the spread of infection.

\section{Validity and reliability of the tool}

The assessment sheet was developed in the English language then, translated to the Arabic language after an extensive review of the literature. The face validity of the tool and the instructional guidelines, its clarity, appropriateness, and relevance were reviewed by five experts in the pediatric nursing field and psychiatry nursing field before using it with the responsive mothers in the study. The Reliability of the tool was by Cronbach's alpha test $\alpha=87 \%$.

\section{Ethical considerations}

The aim of the current study was explained to the mothers in the first part before starting the administered questionnaire, which didn't cause any harm or pain. Also, they assured that the information would be confidential and used for purpose of research only. The participants were informed by the researcher that participating in the study is voluntary; they have the right to withdraw from the study at any time.

\section{Research process}

Preparatory phase

The researchers reviewed the current and past available literature available as textbooks, articles, magazines, and internet search to develop the tools for data collection and prepare the instructional guideline.

\section{A pilot study}

A pilot study was conducted on $10 \%$ of the mothers (13 mothers) of children with autism. It was excluded from the total sample. The clarity and testing of the feasibility of the research process needed for modifications were done based on the results of the pilot study.

\section{Fieldwork}

The actual fieldwork was carried out starting from 15 April 2020 to 30 April 2020. The researchers used the online Google form spreadsheet to create the research. They shared a link to the participant mothers to collect data that included an online administered questionnaire. This link was presented on Face book and Whats App groups. On the first page of the questionnaire, the mothers were informed about the background, objectives, and expected outcomes of the study.

The online administered questionnaire and the ABAS, ASDBI, SSP, and BAI were used twice. For the first time, these were used as a pretest for the assessment of mothers' knowledge about COVID -19 and their reported practice about hand washing technique, how and their level of anxiety. Then, these tools were used another time as a follow- up after one month to evaluate the effect of instructional guidelines on mothers' anxiety level regarding behavioral changes among children with autism during COVID-19. All questions and responses were according to the recent recommendations by the WHO.

The average time spent on mothers' completion of the online administered questionnaire and the ABAS, ASDBI, SSP, and BAI was approximately 30 minutes. Each mother involved in the study was informed about the aim of the current study, the components of the tools, and how to answer the online questionnaire and the scales.

The guidelines were distributed by the researchers to the participant mothers in Whats App and Facebook groups after clarifying the aim of the study, and the researchers explained to the mothers how to use the guidelines.

\section{Statistical analysis}

Data entry and statistical analysis were performed using SPSS for Windows, version 20. Data were presented using descriptive statistics in the form of frequencies and percentages for qualitative variables and mean and SDs for quantitative variables. Differences between the two means tests (t-test) were used. Statistical significance was considered at Pvalue $<0.05$. 


\section{Results}

Table (1): Frequency and percentage distribution of the studied mothers regarding their demographic characteristics $(\mathbf{n}=\mathbf{1 3 0})$.

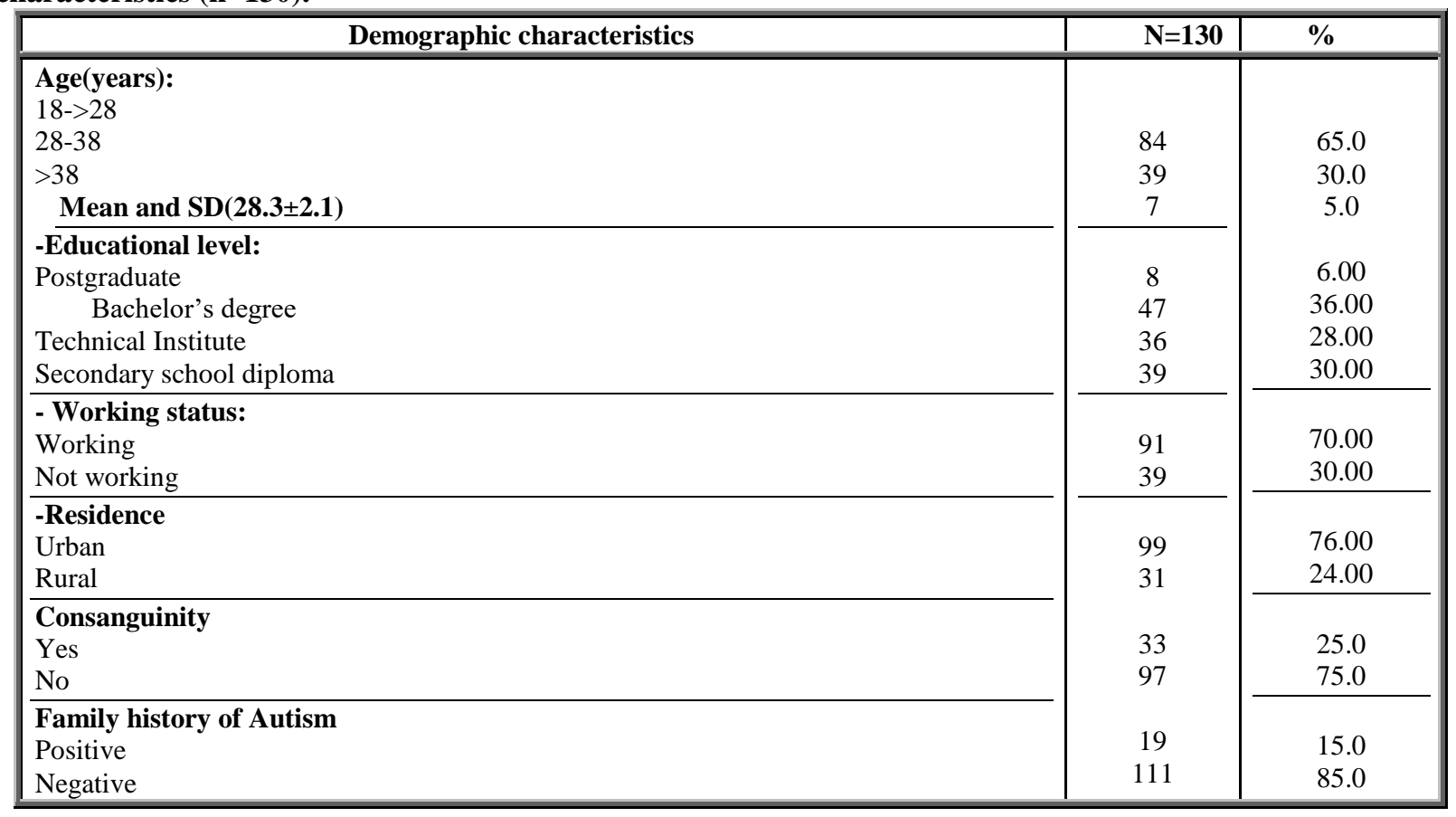

Table (2): Frequency and percentage distribution of the studied children regarding their demographic characteristics $(\mathbf{n}=130)$.

\begin{tabular}{|c|c|c|}
\hline Demographic characteristics & No & $\%$ \\
\hline Mean \pm SD $6.27 \pm 2.47$ & $\begin{array}{l}69 \\
48 \\
13\end{array}$ & $\begin{array}{l}53.0 \\
37.0 \\
10.0\end{array}$ \\
\hline $\begin{array}{cl}\text { Gender } & \\
\bullet & \text { Male } \\
\bullet & \text { Female } \\
\end{array}$ & $\begin{array}{l}97 \\
33 \\
\end{array}$ & $\begin{array}{l}75.0 \\
25.0 \\
\end{array}$ \\
\hline \begin{tabular}{cl}
\multicolumn{2}{l}{ Educational class } \\
- & Nursery \\
- & School-age \\
\end{tabular} & $\begin{array}{l}70 \\
60 \\
\end{array}$ & $\begin{array}{l}54.0 \\
46.0 \\
\end{array}$ \\
\hline $\begin{array}{c}\text { Age (in years) when autism discovered } \\
\begin{array}{ll}- & 1 \\
- & 2->5 \\
- & >5\end{array}\end{array}$ & $\begin{array}{l}23 \\
94 \\
13\end{array}$ & $\begin{array}{l}18.0 \\
72.0 \\
10.0\end{array}$ \\
\hline 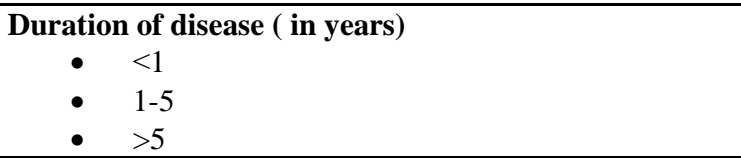 & $\begin{array}{c}83 \\
39 \\
8\end{array}$ & $\begin{array}{r}64.0 \\
30.0 \\
6.0\end{array}$ \\
\hline $\begin{array}{cl}\text { Degree of autism } \\
\text { - } & \text { Mild } \\
- & \text { Moderate } \\
\text { - } & \text { Sever }\end{array}$ & $\begin{array}{l}44 \\
65 \\
21\end{array}$ & $\begin{array}{l}34.0 \\
50.0 \\
16.0\end{array}$ \\
\hline
\end{tabular}


Table (3): Scores of the ABAS-II self-care subscale, the ASDBI subscales, and the SSP

\begin{tabular}{|l|l|c|c|c|c|}
\hline \multicolumn{1}{|c|}{ Test } & \multicolumn{1}{|c|}{ Subscale } & Pre & Post & F & P \\
\hline \hline \multirow{2}{*}{ ABAS-II } & Self-Care & 1.3 & 2.3 & 4.157 & .008 \\
\hline \multirow{5}{*}{ ASDBI } & Hyperactivity & 2.1 & 2.5 & 48.07 & $<0.01$ \\
\cline { 2 - 6 } & Fear of New situations & 0.6 & 0.8 & 12.6 & $<0.01$ \\
\cline { 2 - 6 } & Sleep Regulation Problems & 0.4 & 0.9 & 14.6 & $<0.01$ \\
\cline { 2 - 7 } & Moodiness & 0.5 & 0.7 & 11.7 & $<0.01$ \\
\cline { 2 - 7 } & Irritability & 0.8 & 1.8 & 25.4 & $<0.01$ \\
\cline { 2 - 7 } & Self-Directed Aggression & 1.7 & 2.9 & 0.217 & .65 \\
\cline { 2 - 7 } & Other-Directed Aggression & 0.5 & 0.8 & 3.187 & .008 \\
\hline \multirow{2}{*}{ SSP } & Taste/Smell Sensitivity & 2.6 & 4.6 & 3.256 & .008 \\
\hline
\end{tabular}

* Statistically significant differences

Table (4): Relation between children responses regarding the ASDBI subscales.

\begin{tabular}{|c|c|c|c|c|c|c|}
\hline Subscale & Topic & Response & Pre & Post & $\begin{array}{l}\text { Chi- } \\
\text { square }\end{array}$ & $\mathbf{P}$ \\
\hline \multirow[t]{12}{*}{ Hyperactivity } & \multirow{3}{*}{ Restless } & $\mathrm{N} / \mathrm{A}$ & 39.2 & 62.9 & \multirow{3}{*}{20.71} & \multirow{3}{*}{.001} \\
\hline & & $\mathrm{S} / \mathrm{t}$ & 24.4 & 37.5 & & \\
\hline & & Oft & 1.7 & 36.6 & & \\
\hline & \multirow{3}{*}{ Fidgets } & N/A & 35.9 & 64.5 & \multirow{3}{*}{11.64} & \multirow{3}{*}{.01} \\
\hline & & $\mathrm{S} / \mathrm{t}$ & 35.7 & 37.5 & & \\
\hline & & Oft & 0.0 & 32.2 & & \\
\hline & \multirow{3}{*}{ Climbs on furniture } & N/A & 67.7 & 72.4 & \multirow[t]{3}{*}{78.19} & \multirow[t]{3}{*}{.001} \\
\hline & & $\mathrm{S} / \mathrm{t}$ & 15.3 & 18.5 & & \\
\hline & & Oft & 12.1 & 18.0 & & \\
\hline & \multirow{3}{*}{ Wanders around room } & N/A & 48.2 & 62.3 & \multirow[t]{3}{*}{53.54} & \multirow[t]{3}{*}{.001} \\
\hline & & $\mathrm{S} / \mathrm{t}$ & 28.0 & 35.9 & & \\
\hline & & Oft & 4.9 & 25.8 & & \\
\hline \multirow{12}{*}{$\begin{array}{l}\text { Fear of New } \\
\text { Situations }\end{array}$} & \multirow{3}{*}{$\begin{array}{l}\text { Depressed when things don't } \\
\text { occur at their usual times }\end{array}$} & N/A & 82.6 & 88.9 & \multirow[t]{3}{*}{32.41} & \multirow[t]{3}{*}{.001} \\
\hline & & $\mathrm{S} / \mathrm{t}$ & 9.5 & 11.1 & & \\
\hline & & Oft & 2.6 & 6.3 & & \\
\hline & \multirow{3}{*}{$\begin{array}{l}\text { Resistance for changing from } \\
\text { one activity to another }\end{array}$} & N/A & 46.1 & 57.2 & \multirow[t]{3}{*}{60.39} & \multirow[t]{3}{*}{.001} \\
\hline & & $\mathrm{S} / \mathrm{t}$ & 33.9 & 37.5 & & \\
\hline & & Oft & 7.3 & 19 & & \\
\hline & \multirow{3}{*}{$\begin{array}{l}\text { Depressed when order of the } \\
\text { routine is changed }\end{array}$} & N/A & 68.3 & 79.3 & \multirow[t]{3}{*}{61.50} & \multirow[t]{3}{*}{.001} \\
\hline & & $\mathrm{S} / \mathrm{t}$ & 15.9 & 20.6 & & \\
\hline & & Oft & 4.8 & 11.1 & & \\
\hline & \multirow{3}{*}{$\begin{array}{l}\text { Resistance for changing own } \\
\text { location in room }\end{array}$} & $\mathrm{N} / \mathrm{A}$ & 69.9 & 81 & \multirow[t]{3}{*}{62.81} & \multirow[t]{3}{*}{.001} \\
\hline & & $\mathrm{S} / \mathrm{t}$ & 12.7 & 18 & & \\
\hline & & Oft & 6.3 & 11.1 & & \\
\hline \multirow{12}{*}{$\begin{array}{l}\text { Sleep } \\
\text { Difficulty } \\
\text { regulation }\end{array}$} & & N/A & 68.2 & 88.9 & 19.70 & .001 \\
\hline & Falling problems & $\mathrm{S} / \mathrm{t}$ & 9.5 & 14.3 & & \\
\hline & & Oft & 1.6 & 17.5 & & \\
\hline & & N/A & 68.2 & 81.0 & 50.77 & .001 \\
\hline & more times at night & $\mathrm{S} / \mathrm{t}$ & 11.8 & 16.8 & & \\
\hline & & Oft & 7.2 & 16.8 & & \\
\hline & & N/A & 76.2 & 87.3 & 62.26 & .001 \\
\hline & awake early the rest of the day & $\mathrm{S} / \mathrm{t}$ & 8.7 & 11.7 & & \\
\hline & & Oft & 5.7 & 10.1 & & \\
\hline & & N/A & 87.3 & 96.8 & 11.28 & .01 \\
\hline & Difficult to awake at morning & $\mathrm{S} / \mathrm{t}$ & 3.2 & 7.9 & & \\
\hline & & Oft & 0 & 4.8 & & \\
\hline
\end{tabular}




\begin{tabular}{|c|c|c|c|c|c|c|}
\hline Subscale & Topic & Response & Pre & Post & $\begin{array}{l}\text { Chi- } \\
\text { square }\end{array}$ & $\mathbf{P}$ \\
\hline \multirow{6}{*}{ Moodiness } & \multirow{3}{*}{ fear form no reason } & N/A & 84.1 & 90.5 & \multirow[t]{3}{*}{38.68} & \multirow[t]{3}{*}{.001} \\
\hline & & $\mathrm{S} / \mathrm{t}$ & 9.5 & 11.1 & & \\
\hline & & Oft & 0 & 4.8 & & \\
\hline & \multirow{3}{*}{ Cries for no reason } & N/A & 93.6 & 98.4 & \multirow{3}{*}{\multicolumn{2}{|c|}{ ns }} \\
\hline & & $\mathrm{S} / \mathrm{t}$ & 1.6 & 4.8 & & \\
\hline & & Oft & 0 & 1.6 & & \\
\hline & \multirow{3}{*}{ Angry for no reason } & N/A & 85.8 & 87.3 & \multirow{3}{*}{\multicolumn{2}{|c|}{ Ns }} \\
\hline & & $\mathrm{S} / \mathrm{t}$ & 6.3 & 7.9 & & \\
\hline & & Oft & 4.8 & 7.9 & & \\
\hline & \multirow{3}{*}{ Shift in mood quick } & N/A & 66.7 & 76.2 & \multirow[t]{3}{*}{56.10} & \multirow[t]{3}{*}{.001} \\
\hline & & $\mathrm{S} / \mathrm{t}$ & 19 & 19 & & \\
\hline & & Oft & 4.8 & 14.3 & & \\
\hline \multirow{12}{*}{ Irritability } & \multirow{3}{*}{ Cranky } & N/A & 38.1 & 63.5 & \multirow[t]{3}{*}{34.21} & \multirow[t]{3}{*}{.001} \\
\hline & & $\mathrm{S} / \mathrm{t}$ & 30.2 & 36.5 & & \\
\hline & & Oft & 6.3 & 25.4 & & \\
\hline & \multirow{3}{*}{ Difficult to please } & N/A & 69.8 & 79.3 & \multirow[t]{3}{*}{53.00} & \multirow[t]{3}{*}{.001} \\
\hline & & $\mathrm{S} / \mathrm{t}$ & 15.9 & 15.9 & & \\
\hline & & Oft & 4.8 & 14.3 & & \\
\hline & \multirow{3}{*}{$\begin{array}{l}\text { Takes a long time to calm } \\
\text { down when upset }\end{array}$} & N/A & 71.4 & 77.8 & \multirow[t]{3}{*}{67.02} & \multirow[t]{3}{*}{.001} \\
\hline & & $\mathrm{S} / \mathrm{t}$ & 15.9 & 15.9 & & \\
\hline & & Oft & 6.3 & 12.7 & & \\
\hline & \multirow{3}{*}{ Easily frustrated } & N/A & 50.8 & 65 & \multirow[t]{3}{*}{32.61} & \multirow[t]{3}{*}{.001} \\
\hline & & $\mathrm{S} / \mathrm{t}$ & 28.6 & 30.2 & & \\
\hline & & Oft & 4.8 & 20.6 & & \\
\hline
\end{tabular}

Note: ASDBI: Autism Spectrum Disorder Behavior Inventory; (N/A): means Never/Almost Never; S/t: means sometimes; Oft: means often.

* Statistically significant differences

Table (5): Effect of the instructional guidelines' implementation on the total level of knowledge among studied mothers during COVID-19.

\begin{tabular}{|l|c|c|c|c|c|c|}
\hline \multirow{2}{*}{ Total Knowledge of mothers } & \multicolumn{4}{|c|}{ No=(130) } & \multirow{2}{*}{ X 2} & \multirow{2}{*}{ p-value } \\
\cline { 2 - 5 } & \multicolumn{3}{|c|}{ Pre } & \multicolumn{2}{|c|}{ Post } & \\
\cline { 2 - 5 } & No & \% & No & \% & & \\
\hline Unsatisfactory & 96 & 74.0 & 8 & 6.0 & \multirow{2}{*}{90.35} & \multirow{2}{*}{$<0.05^{*}$} \\
\hline Satisfactory & 34 & 26.0 & 122 & 94.0 & \\
\hline Mean \pm SD & \multicolumn{2}{|c|}{$11.8 \pm 6.7$} & \multicolumn{2}{|c|}{$31.6 \pm 7.2$} & & \\
\hline
\end{tabular}

*Significance at $<0.05 *$ levels

Table (6): Effect of the instructional guidelines' implementation regarding hand washing on the total score of management of autistic children performed as reported by mothers during COVID-19

\begin{tabular}{|l|c|c|c|c|c|c|}
\hline \multirow{2}{*}{ Total practices of mothers } & \multicolumn{4}{|c|}{ No $=(\mathbf{1 3 0})$} & \multirow{2}{*}{ X 2 } & \multirow{2}{*}{ p-value } \\
\cline { 2 - 5 } & \multicolumn{3}{|c|}{ Pre } & \multicolumn{2}{|c|}{ Post } & \\
\cline { 2 - 5 } & No & \% & No & \% & & \\
\hline Unsatisfactory & 103 & 79.0 & 6 & 5.0 & \multirow{2}{*}{49.5} & \multirow{2}{*}{$<0.05^{*}$} \\
\hline Satisfactory & 27 & 21.0 & 124 & 95.0 & \\
\hline Mean \pm SD & \multicolumn{2}{|c|}{$21.2 \pm 56.2$} & \multicolumn{2}{|c|}{$59.4 \pm 52.4$} & & \\
\hline
\end{tabular}

*Significant $p<0.05$ 


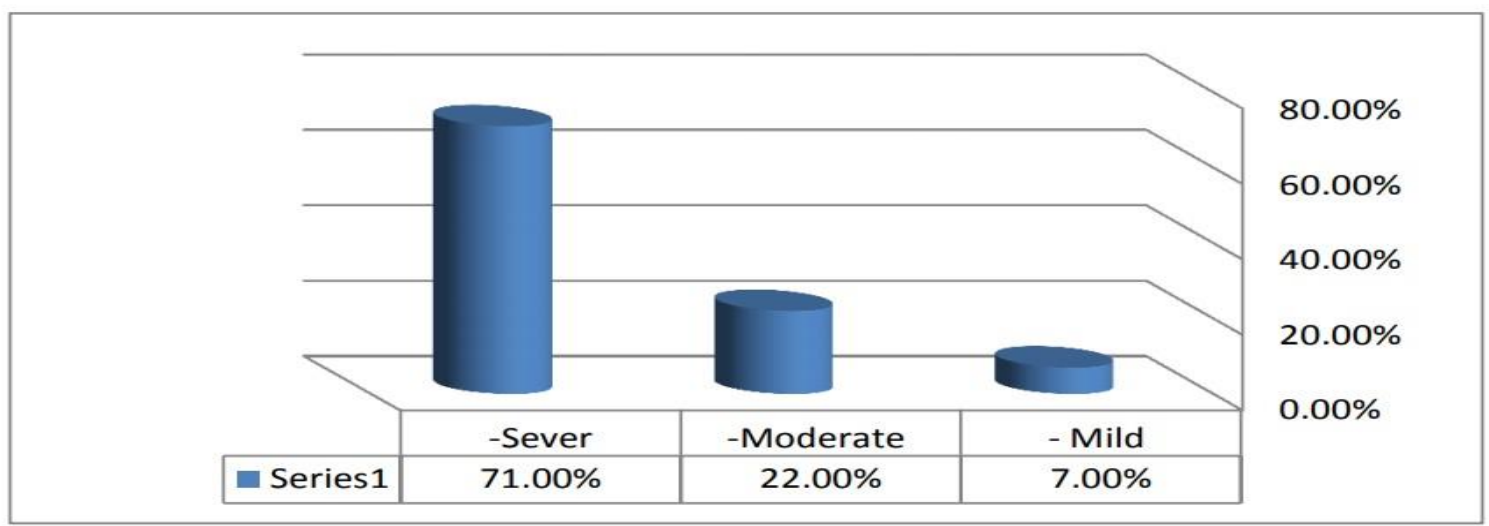

Figure (1): Frequency and percentage distribution of the studied children according to their BAI levels (n=130)

Table (7): Total means scores of mothers' anxiety scores regarding behavioral changes among children with autism during COVID -19 before and after the instructional guidelines' implementation

\begin{tabular}{|c|c|c|c|c|}
\hline \multirow{2}{*}{ BAI average Scores } & \multicolumn{2}{|c|}{ No $=(130)$} & \multirow{2}{*}{$\mathbf{X} 2$} & \multirow{2}{*}{ p-value } \\
\hline & Pre & Post & & \\
\hline BAI average Scores & $39.60 \pm 13.50$ & $23.650 \pm 10.50$ & 18.67 & $<0.001^{*}$ \\
\hline
\end{tabular}

*Significant $p<0.001$

Table (8): Association between mothers' BAI average scores and their total level of knowledge before and after the instructional guidelines' implementation

\begin{tabular}{|c|c|c|c|c|c|c|c|c|c|c|}
\hline \multirow{3}{*}{ BAI level } & \multicolumn{4}{|c|}{ Pre } & \multicolumn{4}{|c|}{ Post } & \multirow{2}{*}{$\mathbf{X} 2$} & \multirow{2}{*}{ p-value } \\
\hline & \multicolumn{2}{|c|}{ Satisfactory } & \multicolumn{2}{|c|}{ Unsatisfactory } & \multicolumn{2}{|c|}{ Satisfactory } & \multicolumn{2}{|c|}{ Unsatisfactory } & & \\
\hline & $\mathrm{No}=$ & $\%$ & No $=$ & $\%$ & $\mathrm{No}=$ & $\%$ & No $=$ & $\%$ & \multirow{2}{*}{34.8} & \multirow{2}{*}{$<0.0001 *$} \\
\hline BAI average level & 34 & 26.0 & 96 & 74.0 & 122 & 94.0 & 8 & 6.0 & & \\
\hline
\end{tabular}

*statistically significant difference

Table (9): Association between demographic characteristics of the studied mothers and their BAI mean \pm SD pre and post the instructional guideline's implementation $(\mathrm{N}=130)$

\begin{tabular}{|c|c|c|c|}
\hline \multirow{2}{*}{ Mothers' characteristics } & \multicolumn{3}{|c|}{ BAI mean \pm SD } \\
\hline & Pre & Post & p-value \\
\hline $\begin{array}{c}\text { Mother age: } \\
-\quad 18->28 \\
-\quad 28-38 \\
-\quad>38\end{array}$ & $\begin{array}{l}36.55 \pm 3.60 \\
35.60 \pm 3.60 \\
34.80 \pm 1.12\end{array}$ & $\begin{array}{l}20.12 \pm 1.60 \\
22.83 \pm 1.13 \\
21.83 \pm 1.13\end{array}$ & $<0.05^{*}$ \\
\hline $\begin{array}{l}\text {-Educational level: } \\
\text { - Postgraduate } \\
\text { - Bachelor's degree } \\
\text { - Technical Institute } \\
\text { - Secondary school }\end{array}$ & $\begin{array}{l}36.80 \pm 1.12 \\
39.55 \pm 3.60 \\
37.60 \pm 3.60 \\
37.80 \pm 1.12 \\
\end{array}$ & $\begin{array}{l}22.83 \pm 1.13 \\
20.12 \pm 1.60 \\
30.12 \pm 1.60 \\
31.83 \pm 1.13\end{array}$ & $<0.05 *$ \\
\hline $\begin{array}{c}\text { - Working status: } \\
\text { - Not Working } \\
\text { - Working }\end{array}$ & $\begin{array}{c}35.60 \pm 3.60 \\
37.80 \pm 1.12\end{array}$ & $\begin{array}{l}23.12 \pm 1.60 \\
21.83 \pm 1.13\end{array}$ & $<0.05^{*}$ \\
\hline $\begin{array}{l}\text { - Residence } \\
\text { - Urban } \\
\text { - Rural } \\
\end{array}$ & $\begin{array}{l}35.60 \pm 3.60 \\
37.80 \pm 1.12 \\
\end{array}$ & $\begin{array}{l}24.12 \pm 2.60 \\
25.83 \pm 1.13\end{array}$ & $<0.05^{*}$ \\
\hline $\begin{array}{c}\text { Consanguinity } \\
\bullet \quad \text { Yes } \\
\bullet \quad \text { No }\end{array}$ & $\begin{array}{l}39.60 \pm 3.30 \\
34.80 \pm 1.13\end{array}$ & $\begin{array}{l}20.12 \pm 2.50 \\
21.83 \pm 1.12\end{array}$ & $<0.05^{*}$ \\
\hline $\begin{array}{c}\text { Family history of Autism } \\
\bullet \quad \text { Positive } \\
\bullet \quad \text { Negative }\end{array}$ & $\begin{array}{l}38.60 \pm 3.60 \\
33.80 \pm 1.12\end{array}$ & $\begin{array}{l}24.14 \pm 2.70 \\
21.63 \pm 1.11\end{array}$ & $<0.05^{*}$ \\
\hline
\end{tabular}

*statistically significant differences 
Table (1): Clarified that more than two-thirds of the studied mothers $(65 \%)$ were in the age group of 18 to less than 28 years, $36 \%$ of them had a university education, $70 \%$ were not working and more than three quarters $(76 \%)$ were living in the urban areas. There was consanguinity between (25\%), and $85 \%$ of them have a negative family history of autism.

Table (2): Represented that the autistic children ' age ranged from 5-12 years, with a mean of $6.27 \pm 2.47$.years. More than half of them $(53 \%)$ were in the age group of 5 to less than 7 years, and three quarters of them $(75 \%)$ were males, and $54 \%$ of them were in the nursery schools. The table also showed that autism was discovered in $72 \%$ of the studied children during the age from 2-5 years, that when autism was discovered, the age of studied children was $2-5$ in $72 \%$ of them, $62 \%$ of them had the disease from less than one year and $50 \%$ of them have a moderate degree of autism.

Table (3): Represented changes occurred in children during covid-19 that reported by mothers of autistic children; they reported increase in restricted and repetitive behaviors, in mannerisms, motor stereotypies, and the vocal stereotypes. Concerning behavioral changes in autistic children during COVID-19 lockdown, changes regarding self-care autonomies, mothers have not mentioned any changes in their children' autonomies regarding the use of the toilet, in washing and dressing ( $F=4.157$; $\mathrm{p}=.008)$. Regarding maladaptive and sensory behaviors, the scores of the ASDBI subscales were significantly increased, and indicated an increasing in problems, specifically regarding hyperactive behaviors, such as motor restlessness, agitation, moving back and forth in the room $(\mathrm{F}=48.07$; $\mathrm{p}$ $<0.01)$, in fears from new situations $(F=12.6$; $p$ $<0.01$ ), and in sleep regulation problems, such as difficult to fall asleep, nocturnal awakenings, and difficult to wake up $(\mathrm{F}=14.6 ; \mathrm{p}<0.01)$.

Also, it represented a significant increasing in aggressiveness, specifically regarding moodiness, the children get scared for no apparent reason, get angry or cries suddenly, their mood change quickly, $(\mathrm{F}=11.7 ; \mathrm{p}<0.01)$, in Irritability, the autistic children have a tantrum, $(\mathrm{F}=25.4 ; \mathrm{p}<0.01)$. No changes were reported by mothers regarding the self care and other-directed aggression subscales (hitting, scratching, and biting themselves or others). Mothers did not report changes among their children regarding the Taste/Smell Sensitivity subscale.

From (Table 4): It observed that the percentage of autistic children who "often" showed that hyperactivity problems increased significantly on all four items involved in the hyperactive subscale. The percentage of autistic children who "often" showed difficult to fall asleep and awake phase, increased significantly. Also, regarding the moodiness and irritability topics, the percentage of autistic children who "often" showed difficulty increased, especially concerning be fear form no reason and change one's mood.

Table (5): It was found that before the instructional guidelines' sending $74 \%$ of the mothers had unsatisfactory knowledge about autism while $94 \%$ of them had satisfactory knowledge after one month after instructional guidelines' sending. A significant improvement was detected in the knowledge of studied subjects $(\mathrm{P}>0.05)$.

Table (6): It was found that the percentage of mothers according to their reported practices regarding hand washing were $95 \%$ satisfactory, $5 \%$ unsatisfactory level after the implementation of the instructional guidelines compared to $26 \%$ good, $79 \%$ poor before the program. The difference was statistically significant where the mean score of reported practices were $(21.2 \pm 56.2)$ before the training, (59.4 \pm 52.4$)$, after one month after instructional guidelines' sending $(\mathrm{P}=<0.05)$.

Figure (1): Illustrated that $(71 \%)$ of the studied mothers had severe anxiety scores and (22\%) of them had moderate anxiety and $7 \%$ had mild anxiety regarding behavioral changes among children with autism during COVID -19 .

It was displayed that significant differences were observed between the BAI average Scores at $\mathrm{p}$ $<0.001$ regarding behavioral changes among children with autism during COVID -19 before and after the instructional guidelines' implementation Table (7).

It was clear from the Table (8): That, there was a significant relation between the studied mothers' anxiety level and their total level of knowledge at pre and post the instructional guidelines' implementation $(\mathrm{P}<0.05)$.

Table (9): Represented that there was a highly statistically significant relationship detected between all demographic characteristics and their anxiety mean scores \pm SD among the studied mothers regarding behavioral changes among children with autism during COVID -19 before and after the instructional guidelines' implementation $\left(r=<0.05^{*}\right)$. A significant decrease was found in the anxiety level among the studied mothers after the instructional guidelines' implementation compared to before the instructional guidelines' implementation.

\section{Discussion}

The results of the current study reflected that instructional guidelines were effective in reducing mothers' anxiety regarding behavioral changes among children with autism during COVID-19 after instructional guidelines implementation. 
The current study results illustrated that more than two-thirds of the studied mothers were in the age group of 18 to less than 28 years, nearly three quarters were not working. This may be attributed to children with ASD's need for special care so that their mothers spent more time with them to manage their needs and not prefer to work.

The current study results showed that changes occurred in autistic children during covid-19 reported by mothers of autistic children an increase in restricted and repetitive behaviors, an increase in mannerisms, an increase in motor stereotypies, and an increase in vocal stereotypes. Concerning behavioral changes among autistic children during COVID-19 lockdown, changes regarding self-care autonomies, mother have not reported any changes regarding their children autonomies as the use of the toilet, washing, or dressing. This is related to that autistic children have sensory interruption make them refuse to use disinfectant solutions because of its odor. This finding is agrees with the study of Renzo, et al., (2020) who stated that and reported the same finding.

Regarding sensory and maladaptive problems as reported in this study, the scores of the ASDBI subscales was also increased and indicated an increasing regarding the problems, especially regarding the hyperactive behaviors, such as motor restlessness, agitation, moving back, and fears from new situations. This may be due to the absence of planned routines; in the lockdown, routine activities such as school, therapy was helped them manage their children.

Similarly, regarding sleep regulation, sleep regulation problems were found, such as difficult to fall asleep, nocturnal awakenings, and difficult to waking up. This result agrees with the study conducted by (Altena et al., 2020), who reported that the problems of sleep are emerging during periods of diseases. This may occurred for children with neuro developmental conditions who may be liable to distribution of their sleep during these periods of changes (Becker \& Gregory, 2020). Less or poor sleep may lead to greater attention difficulties and increased restlessness, that resulting in behaviors and emotional dysregulation (Golberstein et al., 2020).

The results of the current study illustrated significant increasing regarding aggressiveness, especially regarding mood changes, the children get scared without reason, angry or cries suddenly, their mood changes quickly, the children have a tantrum regarding irritability. This is due to sudden changed daily routines, additionally, the children also suddenly difficulty had to cope their lives to a new and sudden events as social distance and isolation and full-time existence with their parents.
The results of the current study revealed that the majority of the studied mothers had severe anxiety scores regarding behavioral changes among children with autism during COVID -19. This is due to the corona virus (COVID-19) pandemic disease and social distance that disrupting routines and lack of access to services as health and rehabilitation center for mothers and children with ASD.

The present study revealed that an improvement in the BAI average scores regarding behavioral changes among children with autism during COVID -19 after the instructional guidelines' implementation. These findings are following those of Walsh et al., (2013) who reported that a stress intervention program was effective for mothers of autistic children and leading to improvements in their stress levels, and providing educational support for mothers of children with ASD help in reducing their stress (McIntyre \& Brown 2018). The present result revealed that a significant relation was found between the studied mothers' anxiety and their total level of knowledge post the instructional guidelines' implementation $(\mathrm{P}<$ 0.05). This confirms the importance of providing instructional guidelines.

The present study reflected that there is a highly statistically significant relationship detected between all demographic characteristics and their anxiety mean scores \pm SD among the studied mothers regarding behavioral changes among their children during COVID -19 and decrease in the anxiety level among the studied mothers after the instructional guidelines' implementation $\left(\mathrm{r}=<0.05^{*}\right)$. Regarding the residence of the studied mothers in rural areas is associated with high mean scores of their stress level before the implementation of the guideline. This may explain that rural areas are differentiated in their values, culture, and believes, and mothers are more stressed because of lack of awareness from social media and difficulty in going to the health center, rehabilitation centers, or the hospital in urban areas when any symptoms appear in their autistic children during COVID -19. Also, the working of the mothers was associated highly significant difference with their stress level. This result may be because working mothers left their children with ASD for a long time when they were in their work without observation and also they need special care increases their stress level about their children who are staying alone at home.

The present study is supported with Gao et al., (2020) who mentioned that educational guidelines were very effective for the mothers and was associated with decrease their levels of anxiety. Also, this result is similar to the results of the study conducted by Sharma et al., (2020) about psychological and anxiety/depression level 
assessment among quarantine people during the COVID 19 outbreak, who reported that anxiety was found among mothers during the COVID 19 outbreak.

\section{Conclusions}

The results concluded that; the instructional guidelines were effective in reducing mothers' anxiety regarding behavioral changes among children with autism during corona virus pandemic outbreaks. Corona virus affected behaviors of autistic children and an increase in restricted and repetitive behaviors, restlessness, sleep disturbance increased, irritability and mood changes. Also, Mothers' anxiety level was severe before the implementation of the guideline and become low after guidelines implementation. There was highly statistically significant difference between mothers' knowledge and their anxiety level regarding behavioral changes among children with autism during corona virus pandemic outbreaks after implementation of the instructional guidelines.

\section{Recommendations}

1- Pediatric nurses should be enrolled children with autism in the intervention program and provide them with information about the topic, using social media methods when not accessible by face to face during the counseling and rehabilitation sessions with mothers.

2- Mothers' classes and educational programs about rehabilitation during COVID -19 should be held at Sohag Governorate for educated and noneducated mothers, and provide parents with adequate and continuous training courses in children's care through online education to maintain social distance.

3- Psychological support should be carried out through the media to help mothers become more resilient during the epidemic disease to prevent complications of emotional disorders.

4- Study can be applied to a large sample in different setting so that the findings can be generalized to a large population.

5- Pay special attention to mothers' anxiety to identify the mental disorders of these mothers to help them deal with their autistic children during this period.

\section{Limitations of the study}

The current study had two limitations; first, the researchers were unable to interview the mothers face-to-face. Second, the study online-based questionnaire method was used during the corona virus pandemic outbreak to avoid infection transmission and places lockdown. So, there was sampling bias being conducted online and restricted to only educated mothers with internet access that does not represent and reflect the whole mothers.

\section{References}

- Al - Masry Al-Youm (2017): 800000 - Egyptians estimated have autism social solidarity minister. Retrieved

fromhttps://www.egyptindependent.com/800000egyptians-estimated-have-autism -social-solidarityminister/Google Scholar.

- Altena, E., Baglioni, C., Espie, C., Ellis, J., Gavriloff, D., Holzinger, B., \& Riemann, D., (2020): Dealing with sleep problems during home confinement due to the COVID-19 outbreak: Practical recommendations from a task force of the European CBT-I Academy. Journal of Sleep Research (pp. e13052), DOI: https://doi.org/10.1111/jsr.13052

- Bai, Y., Yao, L., Wei, T., Tian, F., Jin, D., Chen, L., \& Wang, M., (2020): Presumed asymptomatic carrier transmission of COVID-19. Jama, 323(14), 1406-1407.

- Beck, A., Epstein, N., \& Brown, G., (1988): An inventory for measuring clinical anxiety: psychometric properties. J Consult Clin Psychol; 56(6):893-897.

- Becker, S., \& Gregory, A., (2020): Editorial perspective: Perils and promise for child and adolescent sleep and associated psychopathology during the COVID-19 pandemic. Journal of Child Psychology and Psychiatry, 61(7), 757-759. DOI: https://doi.org/10.1111/jcpp.1327.

- Bixler D., Miller A., \& Mattison C., (2020): SARS-CoV-2-Associated Deaths among Persons Aged <21 Years - United States, February 12July $\quad 31, \quad 2020$. MMWR; 69:13241329, doi:10.15585/mmwr.mm6937e4.

- Campbell, A., (2020): An increasing risk of family violence during the Covid-19 pandemic: Strengthening community collaborations to save lives. Forensic Science International: Reports, 100089. doi:10.1016/j.fsir.2020.100089.

- Cassidy, S., Nicolaidis, C., Davies, B., Rosa, S., Eisenman, D., Onaiwu, M., \& Waisman, T., (2020): An expert discussion on autism in the COVID-19 pandemic. Autism in.

- Centers for Disease Control \& Prevention (CDC). (2020): Demographic Trends of COVID19 cases and deaths in the US reported to CDC. Available at: https://www.cdc.gov/covid-datatracker/index.html\#demographics.

- Chaturvedi, S., (2020): COVID-19, coronavirus, and mental health rehabilitation at times of crisis. Journal of Psychosocial Rehabilitation and Mental Health (pp. 1-2), DOI: https://doi.org/10.1007/s40737-020- 00162-z

- Christensen, D., Braun, K., Baio, J., Bilder, D., Charles, J., Constantino, J., \& Lee, L., (2018): Prevalence and characteristics of autism spectrum 
disorder among children aged 8 years-autism and developmental disabilities monitoring network, 11 sites, United States, 2012. MMWR Surveillance Summaries, 65(13), 1: DOI: https://doi.org/10.15585/mmwr.ss6513a

- Cohen, I., \& Sudhalter, V., (2005): PDD behavior inventory-PDDBI (L. Emberti Gialloreti \& F. Benassi, Trans.). Lutz, FL, USA: Psychological Assessment Resources.

- Gao, J., Zheng, P., Jia, Y., Chen, H., Mao, Y., \& Chen, S., (2020): Mental health problems and social media exposure during COVID-19 outbreak. PLoS One, 15, e0231924.

- Golberstein, E., Wen, H., \& Miller, B., (2020): Coronavirus disease 2019 (COVID-19) and mental health for children and adolescents. JAMA Pediatrics, Advanced online publication. DOI: https://doi.org/10.1001/ jamapediatrics.2020.1456

- Gopalan, G., Bornheimer, L., Acri, M., Winters, A., O'Brien, K., \& Chacko, A., (2018): Multiple family group service delivery model for children with disruptive behavior disorders: Impact on caregiver stress and depressive symptoms. Journal of Emotional and Behavioral Disorders, 26(3), 182192. https://doi.org/10. 1177/1063426617717721

- Harrison, P., \& Oakland, T., (2003): Adaptive behavior assessment system (2nd ed. Los Angeles, CA: Western Psychological Services.

- Hume, K., Waters, V., Sam, A., Steinbrenner, J., Perkins, Y., Dees, B., Tomaszewski, B., Rentschler, L., Szendrey, S., McIntyre, N., White, M., Nowell, S., \& Odom, S., (2020): Supporting individuals with autism through uncertain times. Chapel Hill, NC, USA: University of North Carolina

- Istituto Superiore di Sanità. (2020, August): Indicazioni ad interim per un appropriato sostegno delle persone nello spettro autistico nell'attuale scenario emergenziale SARS-CoV-2 Rapporti ISS COVID-19 [Interim indications for appropriate support to people with ASD in the current SARSCoV-2 emergency]. Rome, Italy: Author

- Leeb R., Price S., \& Sliwa S., (2020): COVID-19 Trends Among School-Aged Children — United States, March 1-September 19, 2020. MMWR; 69:1410-1415. doi:10.15585/mmwr.mm6939e2.

- Lunna, L., Cailey, M., \& Liz, H., (2020): It's Back-to-School amid COVID-19, and Mothers Especially Are Feeling the Strain, Follow @ lizhamel on Twitter, Aug 06.

- Logan, K., Iacono, T., \& Trembath, D., (2017): Systematic review of research into aided AAC to increase social communication functions in children with an autism spectrum disorder. Augment Altern Commun, 33(1), 51-64. DOI: https://doi.org/10.1080/07434618.2016.1267795.
- McIntosh, D., Miller, L., \& Shyu, V., (1999): Development and validation of the short sensory profile. In W. Dunn (Ed.), the sensory profile examiner's manual (pp. 59-73). San Antonio, TX, USA: The Psychological Corporation.

- McIntyre, L., \& Brown, M., (2018): Examining the utilization and usefulness of social support for mothers with young children with autism spectrum disorder, Journal of intellectual \& developmental disability, 43(1), 93-101, https://doi.org/10.3109/ 13668250.2016 .1262534 .

- Ministry of Health and Population Egypt "MOHP" (2020): COVID-19 in Egypt, available at https://www.care.gov.eg/EgyptCare/index.aspx

- Narzisi, A., (2020): Handle the autism spectrum condition during Coronavirus (COVID-19) stay-athome period: Ten tips for helping parents and caregivers of young children. Brain Science, 10(4), 207,

DOI: https://doi.org/10.3390/brainsci10040207

- Renzo, D., Federico, B., Elena, V., Massimiliano, P., Simona, D., Lidia, R., \& Monica, R., (2020): Parent-Reported Behavioural Changes in Children with Autism Spectrum Disorder during the COVID19 Lockdown in Italy. Continuity in Education, 1(1), pp. 117-125. DOI: https://doi.org/10.5334/cie.20 BRIEF REPORT Parent-Reported Behavioural Changes in Children with Autism Spectrum Disorder during the COVID19 Lockdown in Italy

- Seif Eldin, A., Habib, D., Noufal, A., Farrag, S., \& Bazaid, K., (2008): Use of M-CHAT for a multinational screening of young children with autism in the Arab countries. International Review of Psychiatry, 20, 281- 289, https://doi.org/10.1080/09540260801990324.

- Sharma, K., Saji, J., Kumar, R., \& Raju, A., (2020): Psychological and anxiety/depression level assessment among quarantine people during COVID 19 Outbreak. Journal of Drug Delivery and Therapeutics, 10(3), 198-201.

- Walsh, C., Mulder, E., \& Tudor, M., (2013): Predictors of parent stress in a sample of children with ASD: pain, problem behavior, and parental coping. Research in Autism Spectrum Disorders, 7 (2), 256-264.

- World Health Organization (2020): Mental Health and Psychosocial Considerations during COVID-19 Outbreak. http://www.euro.who.int/en/health-

topics/healthemergencies/ coronavirus-covid19/news/news/2020/3/mental-health-and-

psychological resilience-during-the-covid-19pandemic 